\title{
Higher fasting triglyceride predicts higher risks of diabetes mortality in US adults
}

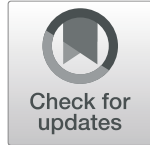

Yutang Wang (D

\begin{abstract}
Background: It is unknown whether higher triglyceride results in higher mortality from diabetes, i.e., diabetes mortality. This study aimed to investigate the association of fasting triglyceride with diabetes mortality.

Methods: This study included 26,582 US adults from the National Health and Nutrition Examination Surveys from 1988 to 2014. Diabetes mortality outcomes were ascertained by linkage to the National Death Index records. Cox proportional hazards models were used to estimate hazard ratios (HRs) and 95\% confidence intervals (Cls) of triglyceride for diabetes mortality.

Results: Higher levels of fasting triglyceride were associated with higher levels of glucose, glycated hemoglobin, insulin, and homeostatic model assessment for insulin resistance at baseline. A 1-natural-log-unit increase in triglyceride (e.g., from 70 to $190 \mathrm{mg} / \mathrm{dL}$ ) was associated with a 115\% higher multivariate-adjusted risk of diabetes diagnosis (odds ratio, 2.15; 95\% Cl, 2.00-2.33). During 319,758 person-years of follow-up with a mean follow-up of 12.0 years, 582 diabetes deaths were documented. Compared with people with triglyceride in the lowest quintile, people with triglyceride in the highest quintile had an $85 \%$ higher risk of diabetes mortality $(\mathrm{HR}, 1.85$; $95 \% \mathrm{Cl}, 1.25-$ 2.73). A 1-natural-log-unit increase in triglyceride was associated with a $40 \%$ higher multivariate-adjusted risk of diabetes mortality. The positive association between triglyceride and diabetes mortality was also presented in subcohorts of participants with or without diabetes.
\end{abstract}

Conclusions: This study demonstrated that higher fasting triglyceride was associated with a higher diabetes mortality risk.

Keywords: Triglyceride, Diabetes, Mortality, Biomarker, Fasting, Association, Risk factor

\section{Introduction}

About 34.1 million adults-or $13.0 \%$ of all US adultshave diabetes, the seventh leading cause of death in the United States with a crude death rate of 25.7 per 100,000 persons per year [1]. The total direct and indirect estimated costs of diagnosed diabetes in the United States in 2017 alone were \$327 billion [1]. Therefore, it is of great importance to identify modifiable factors to decrease diabetes incidence and diabetes-induced death, i.e., diabetes mortality.

Correspondence: yutang.wang@federation.edu.au

Discipline of Life Sciences, School of Science, Psychology and Sport,

Federation University Australia, University Drive, Mt Helen, VIC 3350, Australia
Epidemiological studies frequently show that circulating triglyceride is higher in people with diabetes than that in those without diabetes [2,3]. Higher baseline triglyceride was reported to be associated with new-onset of diabetes in various populations such as Chinese [4], Japanese [5], and Americans [6]. These studies support the notion that higher triglyceride could lead to diabetes.

However, it is unknown whether higher circulating triglyceride leads to higher diabetes mortality. This study aimed to investigate whether higher fasting triglyceride at baseline predicted diabetes mortality using US adults who attended the National Health and Nutrition Examination Survey (NHANES) from 1988 to 2014.

(c) The Author(s). 2021 Open Access This article is licensed under a Creative Commons Attribution 4.0 International License, which permits use, sharing, adaptation, distribution and reproduction in any medium or format, as long as you give appropriate credit to the original author(s) and the source, provide a link to the Creative Commons licence, and indicate if changes were made. The images or other third party material in this article are included in the article's Creative Commons licence, unless indicated otherwise in a credit line to the material. If material is not included in the article's Creative Commons licence and your intended use is not permitted by statutory regulation or exceeds the permitted use, you will need to obtain permission directly from the copyright holder. To view a copy of this licence, visit http://creativecommons.org/licenses/by/4.0/ The Creative Commons Public Domain Dedication waiver (http://creativecommons.org/publicdomain/zero/1.0/) applies to the data made available in this article, unless otherwise stated in a credit line to the data. 


\section{Methods}

\section{Study participants}

This study included participants from NHANES III (1988-1994) and the subsequent eight cycles of NHAN ES from 1999 to 2014. The inclusion criteria included age of $\geq 20$ years and presence of the fasting triglyceride data. This resulted in a cohort of 27,067 participants. The following participants were excluded: those without a follow-up time or with a follow-up time of 0 month $(N=31)$, and those who did not have data on the following parameters: plasma glucose $(N=57)$, blood glycated hemoglobin $\left(\mathrm{HbA}_{1 \mathrm{c}}, N=70\right)$, serum insulin $(N=239)$, physical activity $(N=11)$, and education status $(N=77)$. Therefore, a total of 26,582 participants were included in the final analysis.

\section{Fasting triglyceride}

Fasting status was defined as a fasting time between 8.0 and $23.9 \mathrm{~h}$. The concentration of fasting triglyceride in the serum was retrieved from the NHANES website. Triglyceride was measured enzymatically by using a series of coupled reactions in which triglyceride was hydrolyzed to produce glycerol [7]. Glycerol was then phosphorylated and oxidized to produce $\mathrm{H}_{2} \mathrm{O}_{2}$, and the latter, in the presence of peroxidase, produced a color product that was measured spectrophotometrically at the wavelength of $500 \mathrm{~nm}$. Triglyceride was treated as a continuous variable (natural log-transformed) or a categorical variable (quintiles) in the analysis.

\section{Diabetes-related markers and definition of diabetes}

The following diabetes-related markers were retrieved from the NHANES website: plasma glucose, $\mathrm{HbA}_{1 \mathrm{c}}$ in the whole blood, and serum insulin. Homeostatic model assessment (HOMA) for insulin resistance was calculated using the following formula [8]: (serum insulin in $\mu \mathrm{U} / \mathrm{mL} \mathrm{X}$ plasma glucose in $\mathrm{mmol} / \mathrm{L}) / 22.5$.

Diabetes was defined as fasting plasma glucose $\geq 126$ $\mathrm{mg} / \mathrm{dL}$, or $\mathrm{HbA}_{1 \mathrm{c}} \geq 6.5 \%$, or taking hypoglycemic drugs, or self-reported diagnosis [9].

\section{Diabetes mortality}

Data on diabetes-caused mortality were directly retrieved from NHANES-linked mortality files. To evaluate mortality status and the cause of death, the National Center for Health Statistics conducted probabilistic matching to link the NHANES data with death certificate records from the National Death Index records. The NHANESlinked mortality files used the Underlying Cause of Death 113 (UCOD_113) code to recode all deaths according to the International Classification of Diseases, 9th Revision (ICD-9) or the International Classification of Diseases, 10th Revision (ICD-10). Diabetes mortality was defined as diabetes being listed as an underlying cause of death. Follow-up time was defined as the time (in months) from the time when the blood was drawn at the Mobile Examination Center until death, or until the end of follow-up (i.e., December 31, 2015), whichever occurred first.

\section{Covariates}

Confounding covariates included age (continuous) [2], sex (male or female) [10], ethnicity (non-Hispanic white, non-Hispanic black, Mexican-American, or other) [11], obesity (underweight, normal, overweight, obese, or unknown) [3, 12], education ( $<$ high school, high school, or $>$ high school) [2], poverty-income ratio $(<130,130$ $349 \%, \geq 350 \%$, or unknown) [10, 13], and survey periods (1988-1991, 1991-1994, 1999-2000, 2001-2002, 20032004, 2005-2006, 2007-2008, 2009-2010, 2011-2012, or 2013-2014). NHANES III was conducted in two stages, i.e., from 1988 to 1991 and then from 1991 to 1994, and the subsequent cycles of NHANES were conducted once every 2 years. Lifestyle confounders included physical activity (inactive, insufficiently active, or active) [14, 15], alcohol consumption (never, $<1$ drink per week, 1-6 drinks per week, $\geq 7$ drinks per week, or unknown) [16, 17], and smoking status (past smoker, current smoker, or unknown) [18]. Physical activity was defined as previously reported [15]. In brief, the inactive group was defined as those with no reported moderateto-vigorous leisure-time physical activity; the active group was defined as those who had $\geq 3$ times per week of vigorous leisure-time physical activities, or a combination of 2 vigorous and 2 moderate leisure-time physical activities per week, or $\geq 5$ times per week of any type of leisure-time physical activities (moderate or vigorous or a combination); and insufficiently active group was defined as those who were not inactive and did not meet the criteria for the active group [15]. Clinical confounders included hypercholesterolemia (yes or no) [19], diabetes (yes or no), hypertension (yes, no, or unknown) [2], and family history of diabetes (yes, no, or unknown) [2]. Hypercholesterolemia was defined as total cholesterol $\geq 240 \mathrm{mg} / \mathrm{dL}$ or self-reported diagnosis of hypercholesterolemia [20]. Hypertension was defined as systolic blood pressure $\geq 140 \mathrm{mmHg}$ or diastolic blood pressure $\geq 90 \mathrm{mmHg}$ or prior diagnosis or treatment of hypertension [21].

\section{Statistical analyses}

Data were presented as mean and standard deviation for continuous variables or percentages for categorical variables. Difference in age was analyzed using Student's ttest and differences in non-normally distributed continuous variables (triglyceride, glucose, $\mathrm{HbA}_{1 \mathrm{c}}$, insulin, HOMA for insulin resistance, and C-reactive protein) were analyzed using the Mann-Whitney $U$ test between 
those with or without diabetes. Differences among categorical variables were analyzed using Pearson's chisquare test. Associations of triglyceride with diabetesrelated markers (glucose, $\mathrm{HbA}_{1 \mathrm{c}}$, insulin, and HOMA for insulin resistance) were assessed using the least-squares regression [22], with or without adjustment for confounding factors including age, sex, ethnicity, obesity, education, income, lifestyle factors (physical activity, alcohol consumption, and smoking status), survey period, and clinical confounders (hypercholesterolemia, hypertension, diabetes, and family history of diabetes). Triglyceride, glucose, $\mathrm{HbA}_{1 \mathrm{c}}$, insulin, and HOMA for insulin resistance were natural log-transformed to improve the data distribution before being put into the models. Binary logistic regression was used to assess the association of triglyceride with diabetes diagnosis, with or without adjustment for the above confounders [23]. Cox proportional hazards models were used to calculate hazard ratios (HRs) and 95\% confidence intervals (CIs) of triglyceride for diabetes mortality. Sub-analyses were conducted in sub-cohorts of participants with or without diabetes.

Sensitivity analyses were conducted by further adjustment for baseline glucose, or high-density lipoprotein (HDL) cholesterol and low-density lipoprotein (LDL) cholesterol, as higher levels of glucose [11], lower levels of HDL cholesterol [24], and higher levels of LDL cholesterol $[25,26]$ were associated with new-onset of diabetes. Sensitivity analyses were also conducted by further adjustment for C-reactive protein [27] or the use of lipid-lowering drugs. In addition, sensitivity analyses were conducted when 2-h post-load glucose was considered as a criterium for diabetes diagnosis or when diabetes mortality was defined as diabetes being listed as the leading cause of death.

The null hypothesis was rejected for two-sided values of $P<0.05$. All analyses were performed using SPSS version 27.0 (IBM SPSS Statistics for Windows, Armonk, NY, IBM Corporation).

\section{Results}

\section{General characteristics}

This study included 26,582 (22,909 without diabetes and 3673 with diabetes) US adults with a mean (SD) age of 49 (19) years. Baseline characteristics of the participants are displayed in Table 1.

\section{Association of circulating triglyceride with diabetes- related markers}

Higher triglyceride was independently associated with higher plasma glucose, higher $\mathrm{HbA}_{1 \mathrm{c}}$, higher serum insulin, and higher HOMA for insulin resistance in the whole cohort and sub-cohorts of participants with or without diabetes (Table 2).

\section{Association of circulating triglyceride with diabetes diagnosis}

A 1-natural-log-unit increase in triglyceride (e.g., from 70 to $190 \mathrm{mg} / \mathrm{dL}$ ) was associated with a higher multivariate-adjusted risk of diabetes diagnosis (odds ratio, 2.15; 95\% CI, 2.00-2.33; $P<0.001$; Table 3).

\section{Association of circulating triglyceride with diabetes mortality}

During 319,758 person-years of follow-up with a mean follow-up of 12.0 years, 582 participants died from diabetes. A 1-natural-log-unit increase in triglyceride was associated with a 40,32 , and $45 \%$ higher multivariateadjusted risk of diabetes mortality in the whole cohort, and sub-cohorts of participants with or without diabetes, respectively (Table 4).

Compared with people with triglyceride in the lowest quintile, people with triglyceride in the highest quintile had a higher risk of diabetes mortality in the whole cohort (HR, 1.85; 95\% CI, 1.25-2.73; $P=0.002)$, and in the sub-cohorts of participants with (HR, 1.68; 95\% CI, $1.15-2.45 ; P=0.007)$ or without diabetes (HR, 2.80; $95 \%$ CI, 1.39-5.63; $P=0.004$; Table 5).

\section{Sensitivity analyses}

Sensitivity analyses showed that the association of triglyceride with diabetes mortality was attenuated but remained significant after further adjustment for baseline plasma glucose (Supporting Information Table S1), or HDL and LDL cholesterol (Supporting Information Table S2). Higher triglyceride was associated with higher serum C-reactive protein (Supporting Information Table S3), and further adjustment for serum C-reactive protein did not materially change the association between fasting triglyceride and diabetes mortality (Supporting Information Table S4). The significance of the results remained after further adjustment for use of lipid-lowering drugs (Supporting Information Table S5), or when 2-h postload glucose of $\geq 200 \mathrm{mg} / \mathrm{dL}$ was considered as another criterium for diabetes diagnosis (Supporting Information Tables S6-7), or when diabetes mortality was defined as diabetes being listed as the leading cause of death (Supporting Information Table S8).

\section{Discussion}

Using a representative cohort of US adults, this study, for the first time, revealed that higher fasting triglyceride at baseline was associated with a higher risk of diabetes mortality. Such an association was also presented in subcohorts of participants with or without diabetes.

The finding that higher circulating triglyceride predicted higher diabetes mortality is supported by the following findings of the current study: 1) higher triglyceride was associated with higher plasma glucose, 
Table 1 Baseline characteristics of 26,582 US adults

\begin{tabular}{|c|c|c|c|c|}
\hline & Participants without diabetes & Participants with diabetes & All participants & $P$ value \\
\hline Sample size & 22,909 & 3673 & 26,582 & NA \\
\hline Age, $y$, mean (SD) & $47(18)$ & $61(14)$ & $49(19)$ & $<0.001$ \\
\hline Sex (male), \% & 47.4 & 50.9 & 47.9 & $<0.001$ \\
\hline Ethnicity, \% & & & & $<0.001$ \\
\hline Non-Hispanic white & 46.2 & 38.8 & 45.2 & \\
\hline Non-Hispanic black & 21.3 & 24.8 & 21.8 & \\
\hline Mexican American & 21.8 & 24.1 & 22.1 & \\
\hline Other & 10.8 & 12.2 & 11.0 & \\
\hline Triglyceride, mg/dL, mean (SD) & $130(97)$ & $186(192)$ & $137(117)$ & $<0.001$ \\
\hline $\mathrm{PG}, \mathrm{mg} / \mathrm{dL}$, mean (SD) & $96(10)$ & $156(63)$ & $104(33)$ & $<0.001$ \\
\hline $\mathrm{HbA}_{1 c} \%$, mean (SD) & $5.3(0.4)$ & $7.3(1.8)$ & $5.6(1.0)$ & $<0.001$ \\
\hline Insulin, $\mu \mathrm{U} / \mathrm{mL}$, mean (SD) & $11.1(8.4)$ & $18.5(22.8)$ & $12.1(11.8)$ & $<0.001$ \\
\hline HOMA-IR, mean (SD) & $2.7(2.2)$ & $7.2(9.8)$ & $3.3(4.5)$ & $<0.001$ \\
\hline CRP, mg/dL, mean (SD) & $0.44(0.79)$ & $0.65(1.01)$ & $0.47(0.83)$ & $<0.001$ \\
\hline Obesity, \% & & & & $<0.001$ \\
\hline Underweight & 1.8 & 0.7 & 1.6 & \\
\hline Normal & 34.5 & 14.6 & 31.7 & \\
\hline Overweight & 34.8 & 31.3 & 34.3 & \\
\hline Obese & 28.0 & 51.4 & 31.3 & \\
\hline Unknown & 0.9 & 2.0 & 1.1 & \\
\hline Poverty-income ratio, \% & & & & $<0.001$ \\
\hline$<130 \%$ & 27.8 & 33.5 & 28.6 & \\
\hline $130-349 \%$ & 36.8 & 38.0 & 37.0 & \\
\hline$\geq 350 \%$ & 27.2 & 18.9 & 26.1 & \\
\hline Unknown & 8.1 & 9.5 & 8.3 & \\
\hline Education, \% & & & & $<0.001$ \\
\hline$<$ High School & 30.5 & 43.9 & 32.3 & \\
\hline High School & 26.0 & 24.1 & 25.7 & \\
\hline > High School & 43.5 & 32.0 & 41.9 & \\
\hline Physical activity, \% & & & & $<0.001$ \\
\hline Inactive & 27.5 & 19.1 & 26.4 & \\
\hline Insufficiently active & 38.3 & 30.3 & 37.2 & \\
\hline Active & 34.2 & 50.6 & 36.5 & \\
\hline Alcohol consumption, \% & & & & $<0.001$ \\
\hline 0 drink/week & 16.3 & 27.3 & 17.8 & \\
\hline$<1$ drink/week & 22.8 & 20.3 & 22.5 & \\
\hline 1-6 drinks/week & 21.5 & 11.6 & 20.2 & \\
\hline$\geq 7$ drinks/week & 13.5 & 8.9 & 12.8 & \\
\hline Unknown & 25.8 & 31.9 & 26.7 & \\
\hline Smoking status, \% & & & & $<0.001$ \\
\hline Past smoker & 23.3 & 17.5 & 22.5 & \\
\hline Current smoker & 23.6 & 35.0 & 25.2 & \\
\hline Unknown & 53.1 & 47.5 & 52.3 & \\
\hline Hypercholesterolemia, \% & 32.1 & 53.6 & 35.1 & $<0.001$ \\
\hline
\end{tabular}


Table 1 Baseline characteristics of 26,582 US adults (Continued)

\begin{tabular}{lllll}
\hline & Participants without diabetes & Participants with diabetes & All participants & $P$ value \\
\hline Hypertension, \% & 34.3 & 69.5 & 39.1 & 13.8 \\
Diabetes, \% & 0 & 100 & 40.001 \\
Family history of diabetes, \% & 40.6 & 61.9 & 43.5 & $\mathrm{NA}$ \\
Use of lipid-lowering drugs, \% & 8.3 & 30.2 & 11.3 & $<0.001$ \\
\hline
\end{tabular}

Abbreviations: CRP C-reactive protein, $H b A_{1 c}$ glycated hemoglobin, HOMA-IR homeostatic model assessment for insulin resistance, $N A$ not applicable, $P G$ plasma glucose, $S D$ standard deviation

blood $\mathrm{HbA}_{1 \mathrm{c}}$, serum insulin, and HOMA for insulin resistance; 2) higher triglyceride was associated with higher C-reactive protein, and the latter is an inflammatory marker and an independent predictor for diabetes [27]; and 3) higher triglyceride was associated with a higher risk of diabetes diagnosis.

The mechanism(s) underlying the association between higher triglyceride and higher diabetes mortality is not clear. One possible mechanism could be due to triglyceride-induced inflammation [28] which was supported by the observation of the current study that higher triglyceride was associated with higher levels of C-reactive protein in the circulation. However, the sensitivity analyses showed that further adjustment for Creactive protein did not attenuate the association between triglyceride and diabetes mortality, suggesting that the association between higher triglyceride and higher diabetes mortality may not be mediated by $\mathrm{C}$-reactive protein (or inflammation). Another possible mechanism could be that the change in triglyceride may be copresented with changes in HDL and LDL cholesterol [29]. Sensitivity analyses showed that further adjustment for HDL and LDL cholesterol did attenuate but did not abolish the association between triglyceride and diabetes mortality. Baseline glucose was a strong predictor of future diabetes [27]. Future adjustment for baseline plasma glucose did attenuate but did not abolish the association between triglyceride and diabetes mortality. All these results suggest that circulating triglyceride was an independent risk factor for future diabetes mortality, and the association may be partially mediated by plasma glucose, and HDL and LDL cholesterol.

Epidemiological $[2,3]$ and longitudinal cohort studies $[4-6,30,31]$ showed that higher triglyceride may be a cause of new-onset of diabetes. However, this is not without controversy, as genetic studies provided mixed results. For example, triglyceride-increasing alleles have been reported to be either not associated with [32], or

Table 2 Association of triglyceride (independent variable) ${ }^{a}$ with diabetes markers (dependent variables) ${ }^{a}$ in 26,582 adults

\begin{tabular}{|c|c|c|c|c|c|c|c|c|}
\hline & \multicolumn{2}{|c|}{ Model 1} & \multicolumn{2}{|c|}{ Model 2} & \multicolumn{2}{|c|}{ Model 3} & \multicolumn{2}{|c|}{ Model 4} \\
\hline & $\beta$ & $P$ value & $\bar{\beta}$ & $P$ value & $\beta$ & $P$ value & $\beta$ & $P$ value \\
\hline \multicolumn{9}{|c|}{ All participants $(N=26,582)$} \\
\hline Plasma glucose & 0.275 & $<0.001$ & 0.226 & $<0.001$ & 0.193 & $<0.001$ & 0.114 & $<0.001$ \\
\hline Blood $\mathrm{HbA}_{1 c}$ & 0.223 & $<0.001$ & 0.192 & $<0.001$ & 0.159 & $<0.001$ & 0.074 & $<0.001$ \\
\hline Serum insulin & 0.367 & $<0.001$ & 0.395 & $<0.001$ & 0.268 & $<0.001$ & 0.258 & $<0.001$ \\
\hline HOMA-IR & 0.401 & $<0.001$ & 0.411 & $<0.001$ & 0.290 & $<0.001$ & 0.259 & $<0.001$ \\
\hline \multicolumn{9}{|c|}{ Participants without diabetes $(N=22,909)$} \\
\hline Plasma glucose & 0.200 & $<0.001$ & 0.119 & $<0.001$ & 0.077 & $<0.001$ & 0.074 & $<0.001$ \\
\hline Blood $\mathrm{HbA}_{1 \mathrm{c}}$ & 0.119 & $<0.001$ & 0.086 & $<0.001$ & 0.050 & $<0.001$ & 0.035 & $<0.001$ \\
\hline Serum insulin & 0.358 & $<0.001$ & 0.393 & $<0.001$ & 0.267 & $<0.001$ & 0.268 & $<0.001$ \\
\hline HOMA-IR & 0.366 & $<0.001$ & 0.386 & $<0.001$ & 0.262 & $<0.001$ & 0.261 & $<0.001$ \\
\hline \multicolumn{9}{|c|}{ Participants with diabetes $(N=3673)$} \\
\hline Plasma glucose & 0.286 & $<0.001$ & 0.284 & $<0.001$ & 0.288 & $<0.001$ & 0.292 & $<0.001$ \\
\hline Blood $\mathrm{HbA}_{1 \mathrm{c}}$ & 0.200 & $<0.001$ & 0.215 & $<0.001$ & 0.213 & $<0.001$ & 0.204 & $<0.001$ \\
\hline Serum insulin & 0.250 & $<0.001$ & 0.250 & $<0.001$ & 0.209 & $<0.001$ & 0.216 & $<0.001$ \\
\hline HOMA-IR & 0.342 & $<0.001$ & 0.341 & $<0.001$ & 0.306 & $<0.001$ & 0.315 & $<0.001$ \\
\hline
\end{tabular}

Abbreviations: $\mathrm{HbA}_{1 c}$ glycated hemoglobin, $\mathrm{HOMA}-\mathrm{IR}$ homeostatic model assessment for insulin resistance

${ }^{a}$ Triglyceride, plasma glucose, blood $\mathrm{HbA}_{1 c}$, serum insulin, and HOMA-IR, were natural log-transformed. Model 1: unadjusted; Model 2: adjusted for age, sex, and ethnicity; Model 3: adjusted for all the factors in Model 2 plus obesity, poverty-income ratio, education, physical activity, alcohol consumption, smoking status, and survey period; Model 4: adjusted for all the factors in Model 3 plus hypercholesterolemia, hypertension, diabetes, and family history of diabetes 
Table 3 Natural log-transformed triglyceride and risk for diabetes diagnosis among 26,582 adults

\begin{tabular}{llll}
\hline & Odds ratio & $\mathbf{9 5 \%} \mathrm{Cl}$ & $\boldsymbol{P}$ value \\
\hline Model 1 & 2.52 & $2.38-2.68$ & $<0.001$ \\
Model 2 & 2.64 & $2.47-2.82$ & $<0.001$ \\
Model 3 & 2.38 & $2.22-2.56$ & $<0.001$ \\
Model 4 & 2.15 & $2.00-2.33$ & $<0.001$ \\
\hline
\end{tabular}

Abbreviations: $\mathrm{Cl}$ confidence interval

Model 1: unadjusted; Model 2: adjusted for age, sex, and ethnicity; Model 3: adjusted for all the factors in Model 2 plus obesity, poverty-income ratio, education, physical activity, alcohol consumption, smoking status, and survey period; Model 4: adjusted for all the factors in Model 3 plus hypercholesterolemia, hypertension, and family history of diabetes

positively associated with [33], or inversely associated with diabetes $[6,34,35]$. One of the genetic studies [6] revealed inconsistency between genetic and non-genetic results from the same cohort: triglyceride-increasing alleles were associated with lower new-onset of diabetes, whereas higher baseline circulating levels of triglyceride were associated with higher new-onset of the disease. The reason underlying the observed inconsistency [6] is unknown; it might be due to the selection of genetic alleles or due to that some of the selected genetic alleles have other functions beyond regulating circulating triglyceride.

In people without diabetes at baseline, higher fasting triglyceride predicted impaired glucose tolerance [36], impaired fasting glucose (IFG), and new-onset of diabetes $[4-6,29,30]$. The results of the current study showed that, in participants without diabetes at baseline, higher fasting triglyceride predicted diabetes mortality, supporting the notion that higher triglyceride may be a cause rather than an effect of diabetes.

It has been reported that higher triglyceride was associated with higher all-cause mortality [37, 38]. The current study suggested that the positive association between triglyceride and all-cause mortality may be mediated, at least in part, by higher diabetes mortality. Diabetes can lead to increased risks for cardiovascular disease including heart failure, and glycemic control drugs including sodium-glucose transporter 2 (SGLT2) inhibitors have substantially improved the management of patients with diabetes and reduced patients' cardiovascular complications [39]. Higher fasting triglyceride has been shown to be associated with higher cardiovascular disease mortality [40]. Therefore, reduced cardiovascular disease mortality might be involved in the reduced all-cause mortality associated with lower triglyceride.

\section{Comparisons with other studies and what does the current work add to the existing knowledge}

Although it has been widely reported that higher triglyceride is associated with diabetes prevalence and incidence $[2-6,30,31]$, one important piece of information is missing from the literature, i.e., whether higher triglyceride is associated with higher diabetes mortality. The current study filled this knowledge gap. Diabetes mortality could be defined as diabetes being listed as an underlying cause of death or as the leading cause of death. In either case, higher triglyceride was found to be associated with higher diabetes mortality in the general US population.

\section{Strengths and limitations}

A strength of this study is its large sample size $(N=$ 26,582). This study has several other strengths, such as a prospective study design, the use of a nationally representative sample of US adults with or without diabetes, and adjustment for a large number of confounding factors. This study also has a number of limitations. First, triglyceride was only measured at one time point, which may result in misclassification. Nevertheless, this misclassification tends to result in an underestimate rather than an overestimate of risk in epidemiological analysis due to the effect of regression dilution bias [41]. Second, mortality outcomes were ascertained by linkage to the National Death Index (NDI) records with a probabilistic match, which may also lead to misclassification. However, the Special Projects Branch from the National Center for Health Statistics employed a matching methodology offered by the NDI to determine the best

Table 4 Natural log-transformed triglyceride and risk for diabetes mortality among 26,582 adults

\begin{tabular}{|c|c|c|c|c|c|c|c|c|c|}
\hline & \multicolumn{3}{|c|}{ All participants $(N=26,582)$} & \multicolumn{3}{|c|}{ Participants without diabetes $(N=22,909)$} & \multicolumn{3}{|c|}{ Participants with diabetes $(N=3673)$} \\
\hline & HR & $95 \% \mathrm{Cl}$ & $P$ value & HR & $95 \% \mathrm{Cl}$ & $P$ value & HR & $95 \% \mathrm{Cl}$ & $P$ value \\
\hline Model 1 & 2.62 & $2.33-2.94$ & $<0.001$ & 2.22 & $1.77-2.78$ & $<0.001$ & 1.32 & $1.14-1.54$ & $<0.001$ \\
\hline Model 2 & 2.35 & $2.05-2.68$ & $<0.001$ & 1.77 & $1.37-2.28$ & $<0.001$ & 1.47 & $1.24-1.75$ & $<0.001$ \\
\hline Model 3 & 2.12 & $1.84-2.45$ & $<0.001$ & 1.51 & $1.15-1.99$ & 0.003 & 1.39 & $1.17-1.67$ & $<0.001$ \\
\hline Model 4 & 1.40 & $1.20-1.64$ & $<0.001$ & 1.45 & $1.09-1.92$ & 0.011 & 1.32 & $1.09-1.58$ & 0.004 \\
\hline
\end{tabular}

Abbreviations: $\mathrm{Cl}$ confidence interval, $H R$ hazard ratio

Model 1: unadjusted; Model 2: adjusted for age, sex, and ethnicity; Model 3: adjusted for all the factors in Model 2 plus obesity, poverty-income ratio, education, physical activity, alcohol consumption, smoking status, and survey period; Model 4: adjusted for all the factors in Model 3 plus hypercholesterolemia, hypertension, diabetes, and family history of diabetes 
Table 5 Triglyceride in quintiles and risk for diabetes mortality among 26,582 adults

\begin{tabular}{|c|c|c|c|c|}
\hline Triglyceride in quintiles & No. of participants & No. of deaths & $\mathrm{HR}^{\mathrm{a}}(95 \% \mathrm{Cl})$ & $P$ value \\
\hline \multicolumn{5}{|l|}{ All participants $(N=26,582)$} \\
\hline $\mathrm{Q} 1 \leq 70 \mathrm{mg} / \mathrm{dL}$ & 5225 & 32 & 1 [reference] & NA \\
\hline Q2 71-95 mg/dL & 5321 & 58 & $1.10(072-1.71)$ & 0.656 \\
\hline Q3 96-126 mg/dL & 5296 & 109 & $1.42(0.95-2.13)$ & 0.086 \\
\hline Q4 127-180 mg/dL & 5422 & 141 & $1.35(0.91-2.02)$ & 0.138 \\
\hline $\mathrm{Q} 5 \geq 181 \mathrm{mg} / \mathrm{dL}$ & 5318 & 242 & $1.85(1.25-2.73)$ & 0.002 \\
\hline \multicolumn{5}{|c|}{ Participants without diabetes $(N=22,909)$} \\
\hline $\mathrm{Q} 1 \leq 68 \mathrm{mg} / \mathrm{dL}$ & 4535 & 10 & 1 [reference] & NA \\
\hline Q2 69-92 mg/dL & 4626 & 28 & $1.88(0.91-3.89)$ & 0.089 \\
\hline Q3 93-121 mg/dL & 4540 & 37 & $2.06(1.01-4.19)$ & 0.046 \\
\hline Q4 122-170 mg/dL & 4601 & 47 & $2.06(1.02-4.17)$ & 0.044 \\
\hline $\mathrm{Q} 5 \geq 171 \mathrm{mg} / \mathrm{dL}$ & 4607 & 70 & $2.80(1.39-5.63)$ & 0.004 \\
\hline \multicolumn{5}{|c|}{ Participants with diabetes $(N=3673)$} \\
\hline $\mathrm{Q} 1 \leq 91 \mathrm{mg} / \mathrm{dL}$ & 732 & 44 & 1 [reference] & NA \\
\hline Q2 92-124 mg/dL & 716 & 67 & $1.19(0.81-1.75)$ & 0.389 \\
\hline Q3 $125-166 \mathrm{mg} / \mathrm{dL}$ & 741 & 75 & $1.14(0.77-1.67)$ & 0.516 \\
\hline Q4 $167-234 \mathrm{mg} / \mathrm{dL}$ & 749 & 87 & $1.24(0.85-1.82)$ & 0.266 \\
\hline $\mathrm{Q} 5 \geq 235 \mathrm{mg} / \mathrm{dL}$ & 735 & 117 & $1.68(1.15-2.45)$ & 0.007 \\
\hline
\end{tabular}

Abbreviations: $\mathrm{Cl}$ confidence interval, $H R$ hazard ratio, NA not applicable, No. number, $Q$ quintile

${ }^{a}$ Adjusted for age, sex, ethnicity, obesity, poverty-income ratio, education, physical activity, alcohol consumption, smoking status, survey period,

hypercholesterolemia, hypertension, diabetes, and family history of diabetes

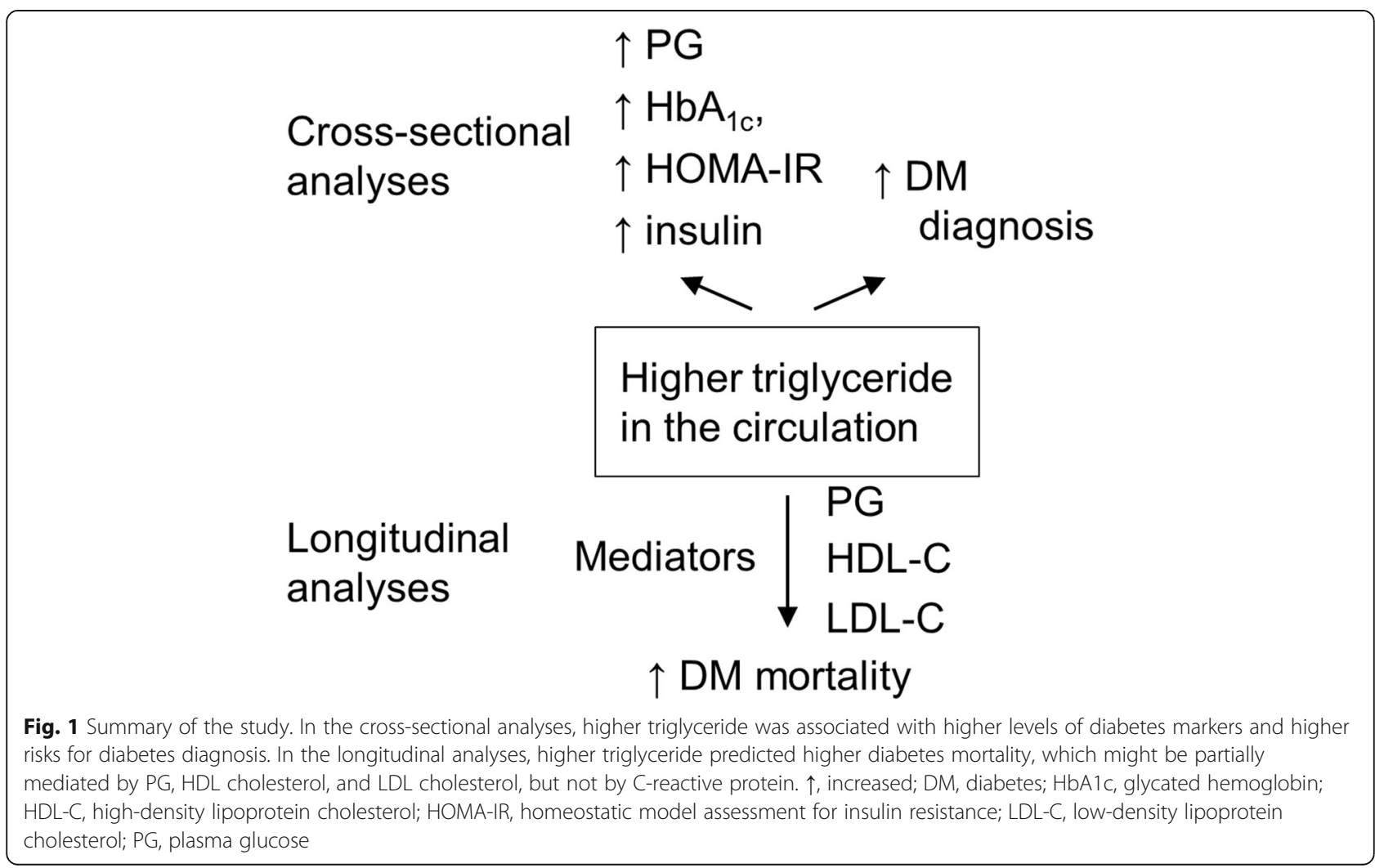


match [42] and a prior validation study showed that the matching method had high accuracy (98.5\%) [43].

\section{Conclusion}

This study demonstrated that higher fasting triglyceride was associated with a higher risk of diabetes diagnosis and diabetes mortality (Fig. 1). Triglyceride may need to be routinely monitored in clinic for the risk assessment for diabetes. In addition, triglyceride may be a therapeutic target for the management of diabetes, and clinical trials on the effectiveness of lowering triglyceride to prevent diabetes mortality are needed.

\section{Abbreviations}

$\mathrm{Cl}$ : Confidence interval; CRP: C-reactive protein; HbA1c: Glycated hemoglobin; HDL: High-density lipoprotein; HOMA: Homeostatic model assessment; HOMA-IR: Homeostatic model assessment for insulin resistance; HR: Hazard ratio; ICD: International Classification of Diseases; LDL: Low-density lipoprotein; NA: Not applicable; NDI: National Death Index; NHANES: National Health and Nutrition Examination Survey; No.: Number; PG: Plasma glucose; Q: Quintile; SD: Standard deviation; UCOD: Underlying Cause of Death

\section{Supplementary Information}

The online version contains supplementary material available at https:/doi. org/10.1186/s12944-021-01614-6.

Additional file 1. Supporting information. Tables S1-S8.

\section{Acknowledgements}

Not applicable.

\section{Author's contributions}

Y.W. had full access to all of the data in the study and takes responsibility for the integrity of the data and the accuracy of the data analysis. Y.W. solely contributed to all aspects of this study. The author read and approved the final manuscript.

\section{Funding}

This research did not receive any specific grant from funding agencies in the public, commercial, or not-for-profit sectors.

\section{Availability of data and materials}

The datasets supporting the conclusions of this article are publicly available on the NHANES website, https://www.cdc.gov/nchs/nhanes/index.htm.

\section{Declarations}

\section{Ethics approval and consent to participate}

The National Center for Health Statistics Research Ethics Review Board (ERB) approved all study protocols (ERB Numbers: NHANES III, NHANES Protocol \#98-12, NHANES Protocol \#2005-06, and NHANES Protocol \#2011-17). All procedures were performed following the guidelines of the Declaration of Helsinki. Written informed consent was obtained from all participants. The participants' records were anonymized before being accessed by the author.

\section{Consent for publication}

Not applicable.

\section{Competing interests}

The author declares that he has no competing interests.
Received: 27 October 2021 Accepted: 13 December 2021

Published online: 20 December 2021

\section{References}

1. Centers for Disease Control and Prevention. National Diabetes Statistics Report. Atlanta, GA: Centers for Disease Control and Prevention, US Dept of Health and Human Services; 2020.

2. Al-Mawali A, Al-Harrasi A, Jayapal SK, Morsi M, Pinto AD, Al-Shekaili W, et al. Prevalence and risk factors of diabetes in a large community-based study in the Sultanate of Oman: STEPS survey 2017. BMC Endocr Disord. 2021;21(1): 42. https://doi.org/10.1186/s12902-020-00655-9.

3. Urrutia I, Martín-Nieto A, Martínez R, Casanovas-Marsal JO, Aguayo A, Del Olmo J, et al. Incidence of diabetes mellitus and associated risk factors in the adult population of the Basque country. Spain Sci Rep. 2021;11(1):3016. https://doi.org/10.1038/s41598-021-82548-y.

4. Zhao J, Zhang Y, Wei F, Song J, Cao Z, Chen C, et al. Triglyceride is an independent predictor of type 2 diabetes among middle-aged and older adults: a prospective study with 8-year follow-ups in two cohorts. J Transl Med. 2019;17(1):403. https://doi.org/10.1186/s12967-019-02156-3.

5. Fujihara K, Sugawara A, Heianza Y, Sairenchi T, Irie F, Iso H, et al. Utility of the triglyceride level for predicting incident diabetes mellitus according to the fasting status and body mass index category: the lbaraki prefectural health study. J Atheroscler Thromb. 2014;21(11):1152-69. https://doi.org/10. 5551/jat.22913.

6. Klimentidis YC, Chougule A, Arora A, Frazier-Wood AC, Hsu CH. Triglycerideincreasing alleles associated with protection against Type-2 diabetes. PLoS Genet. 2015;11(5):e1005204. https://doi.org/10.1371/journal.pgen.1005204.

7. Lipid Laboratory Johns Hopkins. Triglycerides. Laboratory Procedure Manual. NHANES 2005-2006. Available from: https://wwwn.cdc.gov/nchs/data/nha nes/2005-2006/labmethods/trigly_d_met_triglyceride_h717.pdf.

8. Matthews DR, Hosker JP, Rudenski AS, Naylor BA, Treacher DF, Turner RC. Homeostasis model assessment: insulin resistance and beta-cell function from fasting plasma glucose and insulin concentrations in man. Diabetologia. 1985;28(7):412-9. https://doi.org/10.1007/BF00280883.

9. American Diabetes Association. Classification and diagnosis of diabetes: standards of medical Care in Diabetes-2019. Diabetes Care. 2019; 42(Supplement 1):S13-s28. https://doi.org/10.2337/dc19-S002

10. Alam MS, Dyck R, Janzen B, Karunanayake C, Dosman J, Pahwa P. Risk factors, incidence, and prevalence of diabetes among rural farm and nonfarm residents of Saskatchewan, Canada; a population-based longitudinal cohort study. J Diabetes Metab Disord. 2020;19(2):1563-82. https://doi.org/1 0.1007/s40200-020-00693-z.

11. Shaten BJ, Smith GD, Kuller LH, Neaton JD. Risk factors for the development of type II diabetes among men enrolled in the usual care group of the multiple risk factor intervention trial. Diabetes Care. 1993;16(10):1331-9. https://doi.org/10.2337/diacare.16.10.1331.

12. Weir CB, Jan A. BMI classification percentile and cut off points. In: StatPearls. Treasure Island (FL): StatPearls Publishing LLC.; 2021.

13. Kim H, Hu EA, Rebholz CM. Ultra-processed food intake and mortality in the USA: results from the third National Health and nutrition examination survey (NHANES III, 1988-1994). Public Health Nutr. 2019;22(10):1777-85. https://doi.org/10.1017/S1368980018003890.

14. Colberg SR, Sigal RJ, Yardley JE, Riddell MC, Dunstan DW, Dempsey PC, et al Physical activity/exercise and diabetes: a position statement of the American Diabetes Association. Diabetes Care. 2016;39(11):2065-79. https:// doi.org/10.2337/dc16-1728

15. Beddhu S, Baird BC, Zitterkoph J, Neilson J, Greene T. Physical activity and mortality in chronic kidney disease (NHANES III). Clin J Am Soc Nephrol. 2009;4(12):1901-6. https://doi.org/10.2215/CJN.01970309.

16. Crandall JP, Polsky S, Howard AA, Perreault L, Bray GA, Barrett-Connor E, et al. Alcohol consumption and diabetes risk in the diabetes prevention program. Am J Clin Nutr. 2009;90(3):595-601. https://doi.org/10.3945/ajcn.2 008.27382.

17. El Saadany T, Richard A, Wanner M, Rohrmann S. Sex-specific effects of leisure-time physical activity on cause-specific mortality in NHANES III. Prev Med. 2017;101:53-9. https://doi.org/10.1016/j.ypmed.2017.05.029.

18. Willi C, Bodenmann P, Ghali WA, Faris PD, Cornuz J. Active smoking and the risk of type 2 diabetes: a systematic review and meta-analysis. Jama. 2007; 298(22):2654-64. https://doi.org/10.1001/jama.298.22.2654.

19. Lin MJ, Chang YJ, Chen CY, Huang CC, Chuang TY, Wu HP. Influence of hypercholesterolemia and diabetes on long-term outcome in patients with 
stable coronary artery disease receiving percutaneous coronary intervention. Medicine (Baltimore). 2019;98:e16927.

20. Liu L, Miura K, Kadota A, Fujiyoshi A, Gracely EJ, Xue F, et al. The impact of sex on risk of cardiovascular disease and all-cause mortality in adults with or without diabetes mellitus: a comparison between the U.S. and Japan. J Diabetes Complicat. 2019;33(6):417-23. https://doi.org/10.1016/j.jdiacomp.2 019.03.008.

21. Chobanian AV, Bakris GL, Black HR, Cushman WC, Green LA, Izzo JL Jr, et al. Seventh report of the joint National Committee on prevention, detection, evaluation, and treatment of high blood pressure. Hypertension. 2003;42(6): 1206-52. https://doi.org/10.1161/01.HYP.0000107251.49515.c2.

22. Wang Y, Zhang W, Qian T, Sun H, Xu Q, Hou X, et al. Reduced renal function may explain the higher prevalence of hyperuricemia in older people. Sci Rep. 2021;11(1):1302. https://doi.org/10.1038/s41598-020-80250-z.

23. Wang $Y$. Definition, prevalence, and risk factors of low sex hormone-binding globulin in US adults. J Clin Endocrinol Metab. 2021;106(10):e3946-56. https://doi.org/10.1210/clinem/dgab416.

24. Kulick ER, Moon YP, Cheung K, Willey JZ, Sacco RL, Elkind MS. Racial-ethnic disparities in the association between risk factors and diabetes: the northern Manhattan study. Prev Med. 2016;83:31-6. https://doi.org/10.1016/j.ypmed.2 015.11.023.

25. Liu DJ, Peloso GM, Yu H, Butterworth AS, Wang X, Mahajan A, et al. Exomewide association study of plasma lipids in $>300,000$ individuals. Nat Genet. 2017;49(12):1758-66. https://doi.org/10.1038/ng.3977.

26. Fall T, Xie W, Poon W, Yaghootkar H, Mägi R, Knowles JW, et al. Using genetic variants to assess the relationship between circulating lipids and type 2 diabetes. Diabetes. 2015;64(7):2676-84. https://doi.org/10.2337/ db14-1710.

27. Sattar N, Gaw A, Scherbakova O, Ford I, O'Reilly DS, Haffner SM, et al. Metabolic syndrome with and without C-reactive protein as a predictor of coronary heart disease and diabetes in the west of Scotland coronary prevention study. Circulation. 2003;108(4):414-9. https://doi.org/10.1161/01. CIR.0000080897.52664.94.

28. Aung HH, Lame MW, Gohil K, An Cl, Wilson DW, Rutledge JC. Induction of ATF3 gene network by triglyceride-rich lipoprotein lipolysis products increases vascular apoptosis and inflammation. Arterioscler Thromb Vasc Biol. 2013;33(9):2088-96. https://doi.org/10.1161/ATVBAHA.113.301375.

29. Pradhan AD. A new beginning for triglyceride-lowering therapies. Circulation. 2019;140(3):167-9. https://doi.org/10.1161/CIRCULATIONAHA.11 9.038770 .

30. Tirosh A, Shai I, Bitzur R, Kochba I, Tekes-Manova D, Israeli E, et al. Changes in triglyceride levels over time and risk of type 2 diabetes in young men. Diabetes Care. 2008;31(10):2032-7. https://doi.org/10.2337/dc08-0825.

31. Beshara A, Cohen E, Goldberg E, Lilos P, Garty M, Krause I. Triglyceride levels and risk of type 2 diabetes mellitus: a longitudinal large study. J Investig Med. 2016;64(2):383-7. https://doi.org/10.1136/jim-2015-000025.

32. De Silva NM, Freathy RM, Palmer TM, Donnelly LA, Luan J, Gaunt T, et al. Mendelian randomization studies do not support a role for raised circulating triglyceride levels influencing type 2 diabetes, glucose levels, or insulin resistance. Diabetes. 2011;60(3):1008-18. https://doi.org/10.2337/db1 0-1317.

33. Lee KH, Kim OY, Lim HH, Lee YJ, Jang Y, Lee JH. Contribution of APOA51131C allele to the increased susceptibility of diabetes mellitus in association with higher triglyceride in Korean women. Metabolism. 2010; 59(11):1583-90. https://doi.org/10.1016/j.metabol.2010.02.008.

34. Yan J, Hu C, Jiang F, Zhang R, Wang J, Tang S, et al. Genetic variants of PLA2G6 are associated with type 2 diabetes mellitus and triglyceride levels in a Chinese population. Diabet Med. 2015;32(2):280-6. https://doi.org/1 $0.1111 /$ dme.12587.

35. Vaxillaire M, Cavalcanti-Proença C, Dechaume A, Tichet J, Marre M, Balkau B, et al. The common P446L polymorphism in GCKR inversely modulates fasting glucose and triglyceride levels and reduces type 2 diabetes risk in the DESIR prospective general French population. Diabetes. 2008;57(8): 2253-7. https://doi.org/10.2337/db07-1807.

36. Love-Osborne K, Butler N, Gao D, Zeitler P. Elevated fasting triglycerides predict impaired glucose tolerance in adolescents at risk for type 2 diabetes. Pediatr Diabetes. 2006;7(4):205-10. https://doi.org/10.1111/j.13995448.2006.00179.x

37. Thomsen M, Varbo A, Tybjærg-Hansen A, Nordestgaard BG. Low nonfasting triglycerides and reduced all-cause mortality: a Mendelian randomization study. Clin Chem. 2014;60(5):737-46. https://doi.org/10.1373/clinchem.2 013.219881.

38. Arca M, Veronesi C, D'Erasmo L, Borghi C, Colivicchi F, De Ferrari GM, et al. Association of Hypertriglyceridemia with all-cause mortality and atherosclerotic cardiovascular events in a low-risk Italian population: the TGREAL retrospective cohort analysis. J Am Heart Assoc. 2020;9(19):e015801. https://doi.org/10.1161/JAHA.119.015801.

39. Palmiero G, Cesaro A, Vetrano E, Pafundi PC, Galiero R, Caturano A, et al. Impact of SGLT2 inhibitors on heart failure: from pathophysiology to clinical effects. Int J Mol Sci. 2021;22(11):5863. https://doi.org/10.3390/ijms22115863.

40. Shankar A, Mitchell P, Rochtchina E, Wang JJ. The association between circulating white blood cell count, triglyceride level and cardiovascular and all-cause mortality: population-based cohort study. Atherosclerosis. 2007; 192(1):177-83. https://doi.org/10.1016/j.atherosclerosis.2006.04.029.

41. MacMahon S, Peto R, Cutler J, Collins R, Sorlie P, Neaton J, et al. Blood pressure, stroke, and coronary heart disease. Part 1, Prolonged differences in blood pressure: prospective observational studies corrected for the regression dilution bias. Lancet. 1990;335(8692):765-74.

42. National Center for Health Statistics. Office of Analysis and Epidemiology. The Linkage of National Center for Health Statistics Survey Data to the National Death Index - 2015 Linked Mortality File (LMF): Methodology Overview and Analytic Considerations. 2019; Available from https://www. cdc.gov/nchs/data-linkage/mortality-methods.htm.

43. Menke A, Muntner P, Batuman V, Silbergeld EK, Guallar E. Blood lead below $0.48 \mathrm{micromol} / \mathrm{L}(10 \mathrm{microg} / \mathrm{dL})$ and mortality among US adults. Circulation. 2006;114(13):1388-94. https://doi.org/10.1161/CIRCULATIONAHA.106.628321.

\section{Publisher's Note}

Springer Nature remains neutral with regard to jurisdictional claims in published maps and institutional affiliations.

Ready to submit your research? Choose BMC and benefit from:

- fast, convenient online submission

- thorough peer review by experienced researchers in your field

- rapid publication on acceptance

- support for research data, including large and complex data types

- gold Open Access which fosters wider collaboration and increased citations

- maximum visibility for your research: over $100 \mathrm{M}$ website views per year

At BMC, research is always in progress.

Learn more biomedcentral.com/submissions 